\title{
Sonoridades beckettianas: reflexões sobre a voz e a fala no teatro de Samuel Beckett
}

\section{Beckettian sounds: reflections on speech and voice in the Samuel Beckett's theatre}

Manuel Fabricio Alves de Andrade ${ }^{1}$, Cláudia Maria de Vasconcellos ${ }^{2} e$ Suely Master ${ }^{3}$ 


\section{Resumo}

Este estudo apresenta indícios de uma abordagem de preparo vocal para o teatro beckettiano, a partir de reflexões acerca da concepção de Samuel Beckett sobre a voz e a palavra em cena, que se pode inferir de variados registros da sua experiência enquanto encenador ao dirigir montagens de seus próprios textos. No contexto de um tipo de teatro preciso e rigoroso, que exige muito do ato ou atriz, fica evidente a importância dos mesmos em sua realização e no domínio de sua técnica, especialmente no que tange à atuação vocal.

Palavras-chave: Atores; Beckett; voz

\section{Abstract}

This study presents evidences of an approach of a vocal preparation to for the Beckettian theatre from reflections on the Samuel Beckett's conception about the voice and the word on the cene, which can be seen from various records of his experience as a director when driving his own work. In the context of a type of precise and accurate theater, which requires a lot of the performers, it is evident the importance of them on their achievement and mastery of their technique, especially when it comes to vocal performance.

Keywords: Actors; Beckett; voice

11 Ator. Mestre. Integrante dos grupos Grupo de Pesquisa e Estudos
sobre Samuel Beckett - USP e GREVI: Grupo de Estudos em Voz e sobre Samuel Beckett - USP e GREVV: Grupo de Estudos em Voz e Interpretação - UNESP. manuelfabricio@gmail.com . Pesquisa finan-
ciada pela Agência de Fomento: Fundação de Amparo à Pesquisa do Estada pela Agência de Fomento:
Universidade Anhanguera. Profa Dra. Programa de Pós-Graduaçāo m Letras, São Paulo, SP, Brasil. claudia_vasconcellos@terra.com.br Universidade Estadual Paulista. Profa Dra. Programa de Pós-Gra Paub, SP, Brasi. suelymaster@gmail.com

Manuel Fabricio Alves de Andrade, Cláudia Maria de Vasconcellos e Suely Master

\section{Beckett como diretor de seus textos}

A experiência de Samuel Beckett (1906 - 1989), ao dirigir seus textos para teatro, indica como o dramaturgo encarava a realização de suas peças e ainda, oferece uma série de informações tanto para aqueles que almejem encenar sua obra, como para os atores e atrizes que atuarão nela. Beckett deixou indícios de como a interpretação pode ser realizada em seu teatro, tanto no tocante à movimentação, quanto ao trabalho vocal, que, para ele, tinham a mesma importância na encenação.

Beckett deixou registradas suas ideias como encenador de sua própria obra dramática nos seus "Cadernos de Ensaios", os quais, preparou previamente às montagens que dirigiu, esquematizando cenas, descrevendo pormenores sobre a interpretação, o cenário, a luz, entre outros detalhes ${ }^{4}$. Através dessas anotações, da correspondência trocada com amigos e colaboradores, e de relatos de pessoas que conviveram com o dramaturgo, tivemos acesso a dados que nos ajudaram neste estudo. Nosso nteresse em sua experiência como diretor volta-se para a utilização da voz e a enunciação da palavra em seu teatro, a qual nunca estava dissociada dos aspectos físicos da atuação, como veremos adiante; e de como os atores podem realizar a criação vocal na cena beckettiana, tratando-se do tema deste estudo.

A produção dramática de Samuel Beckett, realizada entre 1947 e 1983, participa das transformações ocorridas na dramaturgia ocidental durante o século XX. Nela podemos destacar a presença de enredos ambíguos, o abandono da lógica das ações, o silêncio, a força da imagem e a exigência de uma interpretação não naturalista.

O interesse de Beckett em saber como eram produzidas suas peças se deu logo no início de sua carreira como dramaturgo. A princípio assistiu ensaios de produções francesas e inglesas, nas quais, em geral, desempenhou o papel de assistente de direção. Foi no Schiller-Theater, em Berlim, onde o dramaturgo dirigiu oficialmente sua primeira montagem, com a peça "Fim de partida", em 1967. A partir de então, Becket iria se dedicar cada vez mais à função de diretor de suas próprias peças, o que permitiu que pudesse experimentar e materializar preceitos de seu teatro e aprofundar a radicalidade de seu projeto literário ${ }^{5}$.

Os atores dirigidos por Beckett relatam como ele se mostrava obstinado em conseguir o que queria, mesmo não tendo experiência no fazer teatral. Contudo, Beckett evitava dar aos atores explicações psicológicas ou de cunho emotivo. $\mathrm{O}$ tratamento dado por ele à atuação e às maneiras da elocução era fortemente ligado a uma noção musical e de composição plástica, de materialização do texto teatral, evidência de que estava mais preocupado com a maneira como aquilo seria construído no palco do que com seu significado.

A atriz britânica Billie Whitelaw (1932 -) trabalhou diversas vezes com Beckett, tornando-se sua colaboradora e amiga. Foi dirigida por ele em "Footfalls" (Passos), 1976 ${ }^{4}$ Entre eles: BECKETT, Samuel. Happy Days: Samuel Beckett's pro- $\quad$ sua obra tardia é tema de diversos estudos. Ver: MCMILLAN, D; York (1a ed. 1985). The theatrical notebooks of Samuel Beckett: The shorter plays. James Knowlson (Ed.). New York: Faber and Faber, Grove Press, 1999.

${ }^{5} \mathrm{~A}$ influência de sua prática como diretor no desenvolvimento de 
escrita especialmente para ela; em "Happy Days" (Dias Felizes), 1979; na peça televisiva "Eh Joe", 1988; entre outras produções para o rádio e a TV. Sob a direção de Anthony Page, Whitelaw atuou em "Not I" (Eu Não), 1973, com assistência de direção de Beckett. Para a atriz, as limitações físicas e vocais impostas pela peça criaram uma situação em que era preciso quebrar algumas barreiras como atriz para realizar aquilo que Beckett queria. Whitelaw ficava imóvel em uma cadeira, sobre um pódio, coberta por um manto escuro, o qual deixava visível somente sua boca, impossibilitando-a de enxergar qualquer coisa. Durante a atuação era preciso falar rapidamente e manter uma respiração ofegante, fatores que, segundo a atriz, levaram-na a um colapso de privação de sentidos durante os ensaios, quase chegando a desmaiar (Knowlson, 2007, p. 169). Todavia seu desempenho na peça lhe rendeu a admiração do autor, do público e da crítica.

Em "Passos", a atriz destaca o efeito causado pela economia e contenção dos movimentos em cena. Relembra que ela e Beckett falavam por horas sobre o ir e vir da personagem no palco e das relações entre as partes do corpo, como cada uma delas se relacionavam com as outras. Whitelaw diz que a importância do detalhamento gestual estava no fato de que, para Beckett, esse cuidado e atenção exigiriam maior concentração durante a atuação. A atriz alude à sensação de emitir as palavras como se ela fosse um instrumento musical e recorda que, durante os ensaios, Beckett não a fazia apenas tocar as notas, mas também compor visualmente. Ainda, compara a cena a uma tela que ele pintava e rapidamente apagava, deixando apenas um rastro muito débil do que havia antes (Knowlson, 2007, p. 170).

Segundo Kalb (2000), parte da importância da obra teatral beckettiana consiste no problema que esta coloca sobre a atuação de seus intérpretes, opondo-se à ilusão e à verossimilhança esperada do trabalho do ator. Beckett está ao lado de outros artistas do século XX que estavam engajados numa crítica radical ao pressuposto comum do ilusionismo dramático (Kalb, 2000, p. 5). Para Kalb, a importância de Beckett para o teatro contemporâneo deve ser averiguada em pé de igualdade com o teatro avant-garde, pois a interpretação no palco beckettiano é de uma progressiva e radical originalidade (Kalb, 2000, p. 3), na qual, a fisicalidade dos atores é preponderante, livres de qualquer carga excessiva de interpretação.

\section{Os intérpretes no limite da atuação}

O médico Gottfried Büttner, amigo de Beckett, conta a Knowlson (2007), que para o dramaturgo, a atriz francesa Madeleine Renaud, quando atuou no papel de Winnie em "Dias Felizes", não lhe satisfez completamente. Segundo Büttner, mesmo Beckett achando muito boa a atuação de Renaud, ainda havia muito da atriz na representação, além de um estilo completamente francês. Para Beckett, a atuação deveria ser focada no movimento correto e na musicalidade, livre da presença do ego, desinteressada, despojada de si mesma, com movimentos precisos, sem as afetações do intérprete, como que realizados por Deus, algo como pensou o poeta, romancista, dramaturgo e contista alemão Heinrich Von Kleist (1777-1811), no ensaio "Sobre o Teatro das Marionetes" em 1810, segundo as palavras de Büttner (KNOWLSON, 2007, pg. 188).

Em seu texto, Kleist ([19--]) defende que as marionetes seriam superiores aos bailarinos em seus movimentos, porque teriam a vantagem de estarem livres de qual- quer afetação. Pois, para ele "[...] a afetação aparece, [...], quando a alma (vix motrix) se acha em algum outro ponto que não o do centro de gravidade do movimento" (Kleist, [19--], p.199). O bailarino, também não alcançaria a graça espontânea do movimento de um animal, pois, para o autor, a consciência racional e a distância do reflexo instintivo do homem em relação ao animal tirariam do movimento sua graça espontânea. Enfim, resume seu pensamento da seguinte maneira: "Vemos que, à medida que a reflexão se torna mais obscura e fraca no mundo orgânico, a graça emerge aí tanto mais brilhante e dominante. [...] assim, reaparece novamente a graça, depois que o conhecimento tenha passado como que por um infinito, de tal modo que, ao mesmo tempo, surge no grau mais puro naquela estrutura corporal humana que ou não tem consciência nenhuma ou tem uma consciência infinita, isto é, no manequim, ou no Deus" (Kleist, [19--], p. 201)

Esta qualidade do gesto espontâneo do bailarino no teatro, como pensava Kleist, não racionalizado, desprovido de afetação ou de qualquer intenção que não partisse da comunhão entre a motivação precisa e o movimento, idealizada na figura do manequim ou da marionete, a nosso ver, permite relacioná-la ao trabalho vocal do ator - qual pode realizar uma elocução desprovida de uma assinatura pessoal, afetada emocional e maneirista, focada na musicalidade do texto, como queria Beckett.

Além de Kleist, também é possível relacionar o ideal de interpretação para Beckett à concepção que o poeta, dramaturgo, ator e diretor francês Antonin Artaud (18961948) tinha sobre o papel do intérprete. Para Artaud (2011), o ator em seu "Teatro da Crueldade" é "ao mesmo tempo extremamente importante, e extremamente limitado. Aquilo que chamamos personalidade do ator deve desaparecer completamente. Nesse teatro não há lugar para o ator que impõe seu ritmo ao conjunto, e a cuja personalidade tudo deve se sujeitar" (Artaud, 2011, p. 100). O desejo de Artaud era de que o intérprete se entregasse completamente à experimentação e ao fazer teatral.

Beckett desejava que os atores que atuassem em suas peças não buscassem uma explicação racional ou um entendimento prévio daquilo que teriam que realizar, mas que se atentassem à musicalidade do texto e à fisicalidade propostas na estrutura do mesmo (McMillan; Fehsenfeld, 1988). Este desejo pode ser interpretado como uma exigência de entrega absoluta à experiência teatral que a obra pode proporcionar. Esta é impressão da atriz Maria Alice Vergueiro (1935-) a qual participou do espetáculo "Katastrophé", dirigido por Rubens Rusche em 1986, quando celebrizou "Eu Não" nos palcos brasileiros. Segundo ela, em entrevista a Andrade (2014), Beckett preferia que os atores que atuassem em suas peças não fossem famosos, mas que também não fossem inexperientes demais. Na opinião da atriz, a razão para isto seria "[...] a necessidade da entrega completa desse ator ou atriz [que] não podem levar à cena aquilo que já é deles. O que provavelmente aconteceria com um ator muito conhecido, porque traria sua assinatura, seu jeito de fazer" (Andrade, 2014, p. 90).

\section{Vozes e palavras que ecoam no palco beckettiano}

Uma sugestão que Beckett dava aos atores em suas peças era de que realizas sem uma elocução monocórdia. No entanto, como observa Santos (2013), apesar desta maneira de falar ter se tornado recorrente em seu teatro, não se deve pressupor 
"uma interpretação mecânica, ou absolutamente neutra" (Santos, 2013, p. 66). Essa sugestão de pouca variação de tom na fala solicitada por Beckett, pode ter levado a um clichê beckettiano, como menciona o pesquisador. Todavia, apesar da monotonia, a emissão não deixava de ser rítmica ou vívida. Exemplo disso é o relato da atriz alemã Eva-Katharina Schultz (1922 - 2007), que fez o papel de Winnie, em 1971, no Schiller-Theater, no qual descreve seu desespero em não conseguir atuar durante os ensaios, ao que Beckett lhe ajudava lendo a peça e demonstrando como poderia ser Na opinião da atriz, a maneira como o autor fazia era a melhor Winnie que ele poderia ter. Beckett lia sem modulações, mantendo-se plano, mas, ainda assim, muito vívido e animado (Knowlson, 2007, pg. 188).

Quase a totalidade dos textos de teatro de Beckett fornecem dados nas rubricas que indicam uma atuação precisa, demarcada por uma estrutura rígida, sem muito espaço para o ator colocar sua própria assinatura ou ego, quase que comandada por algo externo, caso bastante explícito na peça "Comédia", por exemplo. Nesta, a interpretação dos atores é reduzida à face e à voz, já que estão metidos em grandes jarros somente com a cabeça à mostra, iluminadas por um refletor instalado no proscênio. Vozes e falas são comandadas pela luz e dependem da intensidade da mesma para realizarem variações somente de intensidade de voz (volume), já que o autor determina que estas sejam monocórdias. Na rubrica inicial encontramos as seguintes indicações: "Suas falas são provocadas por um refletor cuja luz se projeta apenas sobre cada um dos rostos. [...] Rostos impassíveis durante toda a peça. Vozes sem colorido salvo quando alguma expressão for indicada. Ritmo sempre rápido." (Beckett, 2010, [tradução de R. Rusche], [grifo nosso]).

Esslin (1986) conta-nos, detalhadamente, a maneira como Beckett imaginava a emissão da fala em "Comédia", reforçando o caráter rigorosamente preciso da mesma. Segundo o crítico, Beckett concebia a divisão do texto da peça em três partes: "Coro (todas as personagens falando ao mesmo tempo); Narração (na qual as personagens falam sobre os acontecimentos que levaram à catástrofe); e Meditação (na qual refletem sobre seu estado infinitamente suspensas no limbo)". ${ }^{6}$ (Esslin, 1986, p 372 [tradução nossa]). A peça termina, mas recomeça do coro, repetindo as três partes novamente. Entretanto, ela deve ser repetida mais rápida e mais suave do que da primeira vez. Esslin descreve a progressão imaginada por Beckett: "Se a velocidade do primeiro Coro é 1 e o seu volume 1, a seguir, a velocidade da primeira Narração deve ser 1 mais 5 por cento e seu volume ter menos 5 por cento. A velocidade do segmento seguinte, a primeira Meditação deve, então, ser ( 1 mais 5 por cento) mais 5 por cento, e o seu volume (1 menos 5 por cento) menos 5 por cento" 7 (ESSLIN, 1986, p. 372 [tradução nossa]). Esta progressão ascendente em velocidade e decrescente em intensidade (volume) poderia levar a uma repetição ad infinitum, apesar da quantificação finita dessas medidas, conforme Esslin analisa.

Do ponto de vista da atuação, pode-se inferir que o detalhamento na progressão proposto por Beckett exigiria uma técnica vocal sofisticada dos atores que realizassem a peça. Os intérpretes da primeira montagem de "Comédia" na Alemanha, em

"Chorus (all characters speaking simultaneously); Narration (in which Meditation (in which they reflect on their state of being endlessly susthe characters talk about the events that led to the catastrophe); and pended in limbo)"

1963, ao que parece, não agradaram a Beckett, que não viu neles envergadura suficiente para realizarem a peça. "Podemos associar esta 'envergadura' a versatilidade, capacidade de expressão de nuances, domínio expressivo, de uma forma geral" (Santos, 2013, p. 69). Talvez por isso, a insatisfação de Beckett possa ser entendida como o desejo por intérpretes capazes de administrar com clareza pressupostos técnicos como a velocidade da fala e a intensidade da emissão vocal dentro da interpretação, o que certamente exige percepção rítmica e uma grande consciência de suas qualidades vocais e expressivas.

Ryngaert (1998) coloca Beckett ao lado de dramaturgos que mudaram aquilo que se julgava ser definitivo como linguagem teatral, forçando novos entendimentos sobre a construção da cena e da forma da atuação exigida dos atores, já que ocupam um lugar crucial na realização do texto dramático, sobretudo dos contemporâneos, nos quais o uso da pontuação ou a construção lexical não levam a uma ideia unívoca do autor, deixando ao intérprete a função de dar vida ou sentido ao texto (Ryngaert 1998, p. 48-9). Isto acontece na dramaturgia de Beckett, propondo um teatro lacônico, fortemente alicerçado no ato de falar e que, por este motivo, a ação de falar se torna tão importante em seu teatro.

Apesar do teatro de Beckett estar alicerçado no ato de falar, como aponta Ryngaert (1998), não era fundamental para o dramaturgo que o texto fosse bem compreendido pela plateia. Expressivo nesse sentido é o texto curto "Eu não". Nesta peça, o que se vê é uma cena imersa na escuridão onde há somente uma boca feminina suspensa no vazio e uma figura humana indistinta, imóvel na penumbra, o Ouvinte. A personagem Boca profere um discurso vertiginoso, quase incompreensível, de fragmentos que descrevem passagens da vida de uma velha senhora já setuagenária, a qual, não é possível afirmar, ser dela a boca ou não. A fala de Boca tem início antes da luz da plateia se apagar completamente e só termina quando esta volta a se acender (Beckett, 2006).

Durante sua primeira montagem, realizada em Nova lorque em 1972, por carta, Beckett indica ao diretor Alan Schneider, como a atriz poderia proferir o texto: "Eu a escuto sem fôlego, urgente, febril, rítmico, arquejante, sem excessiva relação com a inteligibilidade. Dedique-se menos ao entendimento e mais aos nervos da plateia que deve, de certo modo, 'compartilhar da confusão da personagem'"18 (Beckett, Schneider, 1999, p. 283 [tradução de CAVALCANTI, 2006, p. 88]). Fica clara a importância dada por Beckett à criação de uma massa sonora, mais do que a comunicação de um sentido estável e claro da fala da personagem. O entendimento lógico e absoluto, de um ponto de vista cartesiano, do que falam as personagens beckettianas não é mais mportante do que a relação entre as sonoridades das palavras, os silêncios e as imagens dentro da encenação.

Lembramo-nos novamente de Artaud (1999), que acreditava que a palavra havia se ossificado, que estava congelada, trancafiada em seu próprio significado pela restrição imposta por uma terminologia esquemática. Para ele, "A obsessão pela palavra

"If the speed of the first Chorus is 1 and its volume 1 , then the speed then be ( 1 plus 5 percent) plus 5 percent, and its volume ( 1 minus of first Narration must be 1 plus 5 percent and its volume 5 minus percent) minus 5 percent".

percent. The speed of the following segment, the first Meditation, must

Manuel Fabricio Alves de Andrade, Cláudia Maria de Vasconcellos e Suely Master 
clara, que diz tudo, leva ao ressecamento das palavras" (Artaud, 1999, pg. 146). O desejo de Artaud era livrar o teatro ocidental da opressão do sentido, da racionalização e dos vínculos psicologizantes a que o texto dramático condenara a cena. Ao projetar seu "Teatro da Crueldade", Artaud, se interessava por uma concepção "encantatória da Palavra" (Artaud, 2011, p.71). Segundo ele

\section{Se o teatro não ultrapassa o domínio daquilo que as palavras tomadas em seu sen- ido mais corrente, em sua acepção mais normal e ordinária podem atingir, isto se espécie de imenso auto de ocorrencia psicológica que fazem de todo teatro uma

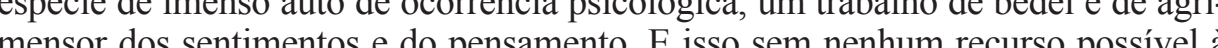
.

O visionário francês imaginava uma palavra que se materializasse em cena juntamente com a ação dos atores, que se aproximaria de um rito sagrado. Essa ação, segundo ele, seria orgânica e se dirigiria "[...] diretamente aos órgãos da sensibilidade nervosa" (Artaud, 2011, p. 117). Num desejo de que tal teatro se destinasse "sobretudo aos nervos e não à razão" (Artaud, 2011, p. 118). Semelhante era o desejo de Beckett, que supomos a partir dos exemplos citados acima de "Comédia" ou "Eu Não", nas quais, ele não estava preocupado com o entendimento pleno dos espectadores através da audição clara de todo o texto, mas antes, de como as palavras poderiam se articular sonoramente na construção da cena, agindo diretamente nos "nervos da plateia".

\section{Dirigindo Beckett no Brasil}

No Brasil, alguns diretores de teatro que se dedicaram a montar peças de Samuel Beckett também se preocuparam em entender a problemática da atuação e da emissão vocal de seus atores. O diretor Rubens Rusche, que fez sua estreia na direção com "Katastrophé", em 1986, ocasião em que reuniu os textos curtos "Eu Não", "Comédia", "Cadeira de Balanço" e "Catástrofe", também acredita que o teatro beckettiano exige uma entrega total do ator, no mesmo sentido das impressões de Billie Whitelaw e Maria Alice Vergueiro acima citadas. Em entrevista a Andrade (2014) Rusche expõe sua leitura do teatro beckettiano, na qual menciona a ineficácia da linguagem em exprimir as singularidades eficientemente e que a atuação é afetada por isso. Para o diretor, Beckett é o primeiro dramaturgo a trazer o corpo, de fato, para a cena e sua leitura da obra beckettiana tem grande influência artaudiana. "Beckett é pós-Artaud e leva muito a sério as observações que este fez. Principalmente aquela de que havia uma ausência do corpo no teatro. Quer dizer, havia uma palavra desencarnada, uma voz sem corpo. Com Beckett, pela primeira vez, vamos ter no palco o nascimento de um teatro onde há um corpo e uma palavra profundamente vinculada a esse corpo, sem nenhuma separação dele" (Andrade, 2014, p. 114). E destaca, ainda

a musicalidade presente nesta fala, elaborada por Beckett como uma partitura que está totalmente vinculada com a cena que se cria no palco.

Para o diretor Gerald Thomas (1954-), que realizou em 1984 o espetáculo "Quatro vezes Beckett", quando foram encenados os textos "Teatro 1", "Teatro 2", "Aquela Vez" e "Nada", da mesma maneira como na prosa beckettiana, a voz de um livro não pode ter semelhança com a voz humana, pois não se sabe a fonte desta voz, se vem da cabeça da personagem, de um narrador etc.; o mesmo não pode acontecer com a voz no teatro e isso ele procura preservar em suas montagens através de um trabalho vocal distante do realismo (Thomas, 1988, p. D4)

Lenerson Polonini, diretor da Cia. Nova de Teatro, que no início dos anos 2000 encenou diversos textos beckettianos, entre eles, "Eu Não", "Vaivém", "Catástrofe", "Improviso de Ohio", conta a Andrade (2014) acredita que um ator comprometido é de importância ímpar para se montar Beckett. Destaca também a musicalidade da escrita beckettiana e que o modo de falar deve se distanciar do naturalismo. "É uma estrutura musical. Os silêncios, as pausas depois de blocos de falas enormes. É bonito. São possibilidades infinitas de se buscar essa musicalidade através dos textos do Beckett" (Andrade, 2014, p. 81).

Antunes Filho (1929-), que realizou uma montagem de "Esperando Godot" em 1977, também traz reflexões interessantes. Para Antunes Filho (2006), o problema de se trabalhar com Beckett no Brasil é cultural, uma vez que para entender o dramaturgo é preciso um grande embasamento sobre a modernidade e a pós-modernidade. A partir deste ponto, a dificuldade é de ordem técnica, já que os atores não estariam preparados para atuarem no teatro beckettiano. Estes, quando começam os ensaios já querem trazer sentimento, emoções etc., não se dando conta de que as peças são jogos de palavras.

\section{Jogue palavras, procure se divertir, o ritmo é importante, é uma espécie de 'clownerie' um com o outro, porque um precisa do outro. [...] $\mathrm{O}$ ator, quando faz Beckett, começa pela angustia e faz uma meleca de sentimentos. Tá errado [sic]. Tem que fica no jogo, animar um ao outro e depois perguntar: 'Por que estou fa- zendo isso? '; aí vem o sentimento. [...] É uma máquina, o sentimento em Becket vem depois da palavra (Antunes Filho, 2006, p.6)}

\section{Novas percepções da expressividade vocal}

Féral (2009) coloca Beckett, juntamente com Heiner Müller (1929-1995), como autores de fundamental importância para a compreensão da dramaturgia contemporânea. Acredita que o trabalho de montagem de seus textos serviria para auxiliar na formação de novos atores, devido as suas obras dialogarem diretamente com a "performatividade" do teatro contemporâneo (Féral, 2009, p.261). Certamente, o teatro beckettiano, ao lado de outras ações realizadas por teatrólogos desde o início do século $X X$, muito tem a contribuir no sentido de uma nova percepção do uso da voz e da fala no teatro, o que vem sendo desenvolvido no âmbito pedagógico teatral em oposição a uma concepção já ultrapassada de impostação vocal.

A impostação teria "[...] como pretensão ampliar as possibilidades vocais do ator, mas por não respeitar suas características psicofísicas, acaba tornando-o profunda- 
mente artificial e limitado na busca da expressividade" (Master, 2007, p. 40). Fuse 2013) observa que não há como ignorar que a retomada dos escritos de Artaud influenciaram fortemente as pesquisas sobre a voz em meados do século passado, vide o exemplo de Jerzy Grotowski (1933-1999). Também o contato com as artes teatrais do oriente e do modo de falar de artistas de diferentes partes do mundo, afetou a "[... percepção da força da palavra na construção de imagens, não apenas através do seu significado, mas também pelo potencial expressivo da energia liberada pela emissão dos fonemas" (Fuser, 2013, p. 462).

Talvez, para um trabalho com o teatro de Beckett, em contraposição à proposta de impostação, seja interessante, por exemplo, a busca por uma técnica que parta do conhecimento da anatomia e da fisiologia da produção da voz, a qual vem ganhado força na atividade de preparação mais contemporânea. Tem-se dado mais valor a um desenvolvimento da voz que ajude o ator, por exemplo, a entender mehor - e ampliar - sua capacidade de ressonância, considerando toda uma implicação fisiológica mais do que o uso poético que tem sido feito desta palavra (Master 2007, p. 41) ou mesmo que leve o ator a explorar outras qualidades de voz a partir do entendimento correto do que seja ressonância; que o leve a explorar seu potencial articulatório em função de diferentes sonoridades e para além da precisão e do virtuosismo; ainda, a experimentar diferentes registros e tessituras de voz, inclusive nos seus limites. Enfim, que possibilite ao intérprete perceber "vícios e estereótipos de interpretação", afastando-o assim da artificialidade que resulta do ensino preconizado por "escolas ultrapassadas como a dos velhos diseurs franceses" (Master 2007, p. 44). Um tipo de abordagem onde o conhecimento da fisiologia se transforme em recursos vocais expressivos e seja - porque não? - ponto de partida de um processo de criação vocal.

Para o caso do teatro tardio beckettiano, pensamos em uma preparação que leve em conta a percepção rítmica do discurso, as variações de frequência (tom) e in tensidade de voz (volume), a relação entre movimento e elocução, o uso das sonoridades diversas da fala, como os ruídos das consoantes ou da respiração, como partes integrantes da materialização cênica de um texto. Como vimos, estas eram questões importantes para Beckett e guiar-se pelas mesmas, certamente, possibilitará um enriquecimento do preparo vocal tanto de atores e atrizes em formação, quanto dos profissionais atuantes.

\section{Considerações finais}

Em meio às reflexões possibilitadas por este estudo, é interessante destacar quanto o teatro de Beckett pode exigir uma atuação vocal com grande rigor técnico, sem, no entanto, estar desvinculada de uma fisicalidade também rigorosa e que força o ator a romper seus limites, numa atitude de entrega absoluta ao fazer teatral situação expressas pelas atrizes Billie Whitelaw e Maria Alice Vergueiro e também pelos diretores Rubens Rusche e Lenerson Polonini. Entendemos este rompimento, todavia, não como uma insubordinação do intérprete à obra, mas sim como uma possibilidade de refinamento de sua técnica e de uma experiência de apropriação de suas capacidades como artista.
Abrem-se possibilidades de aprofundamento do trabalho da preparação vocal tanto para a cena beckettiana, quanto para o teatro em geral. De conceder à fala possibilidade de ser trabalhada e burilada como os demais componentes da encenação teatral, não estando nem sobreposta, nem subjugada a eles, mas antes, como um elemento sobre o qual o ator pode trabalhar concretamente sem preocupar-se com déficits por falta de instrumentalização. A assimilação da técnica vocal preparatória possibilitará desenvolver novas nuances para a fala e permitirá ao ator ampliar seus limites na atuação.

\section{Referências}

ANDRADE, M. F. A. Sonoridades beckettianas: a criação vocal do intérprete. 2014. Dissertação (Mestrado em Artes). Instituto de Artes, Universidade Estadual Paulista, São Paulo, 2014

ARTAUD, A. O teatro e seu Duplo. Tradução de T. Coelho. São Paulo: Martins Fontes 1999.

Linguagem e Vida. Organização J. Guinsburg, S. F. Telesi e A. Mercado Neto. Tradução de J. Guinsburg, S. F. Telesi, R. C. Rocha e M. L. Pereira. Perspectiva: São Paulo, 2011.

BECKETT, S. The Complete Dramatic Works. London: Faber and Faber, 2006.

Comédia. Tradução de R. Rusche e L. R. Benati. [s/e], [1985].

Eu Não. Tradução de R. Rusche. [s/e], [1985]

SCHNEIDER, A. No Author better served: the correspondence of Samuel Beckett and Alain Schneider. Edited by M. Harmon. Cambridge, Massachusetts, London, England: Harvard University, 1998.

CAVALCANTI, I. Eu que não estou aí onde estou: o teatro de Samuel Beckett. Rio de Janeiro: 7 Letras, 2006

ESSLIN, M. Samuel Beckett and the art of radio. In: GONTARSKI, S. (Org.). On Beckett: Essays and Criticism. New York: Grove Press, 1986.

FÉRAL, J. Teatro performativo e pedagogia: entrevista com Josette Féral. Sala Preta - Revista da PPG em Artes Cênicas - ECA - USP, vol. 9, n. 1, 2009. Disponível em <http://www.revistas.usp.br/salapreta/issue/view/4701/showToc>. Acesso em: 14 ago. 2013.

ANTUNES FILHO. Espetáculo de Clowns. Folha de S. Paulo. Mais!, 09/04/2006, p. 6. Disponível em: <http://acervo.folha.com.br/resultados/buscade_talha$\mathrm{da} /$ ?utf8=\%E2\%9C\%93\&fsp=on\&all_words=beckett\&phrase=\&words=\&without

Manuel Fabricio Alves de Andrade, Cláudia Maria de Vasconcellos e Suely Master 
words $=$ \&initial_date $=01 \% 2 \mathrm{~F} 04 \% 2 \mathrm{~F} 20068$ final_date $=10 \% 2 \mathrm{~F} 04 \% 2 \mathrm{~F} 20068$ date $\% 5 \mathrm{~B}-$ day $\% 5 \mathrm{D}=\&$ date $\% 5 \mathrm{Bmonth} \% 5 \mathrm{D}=$ \&date\%5Byear\%5D=\&group_id=0\&theme_id=0\&commit. $x=618$ commit. $y=148$ commit=Enviar>. Acesso em: 15 set. 2013.

FUSER, R. A. B. Outras práticas teatrais modernas e contemporâneas: a formação do ator. In: FARIA, J. R. História do teatro brasileiro: do modernismo às tendências contemporâneas. São Paulo: Perspectiva: Edições SESCSP, 2013. Vol. 2.

KALB, J. Beckett in Performance. Cambridge, New York, Port Chester, Melbourne, Sydney: Cambridge University, 2000.

KLEIST, H. V. Sobre o teatro de marionetes. Tradução, apresentação e notas de J. Guinsburg. REVISTA USP. Superintendência de Comunicação Social da USP, n. 17, p. 196-201, [19-?]. Disponível em: <http://www.usp.br/revistausp/17/16-heinrich.pdf> Acesso em: 22 ago. 2013.

KNOWLSON, J. Dammed to Fame: the life of Samuel Beckett. London: Bloomsbury, 1996.

; KNOWLSON, E. Beckett remembering; remembering Beckett: uncollected interviews with Samuel Beckett and memories of those who knew him. London: Bloomsbury, 2007.

MASTER, S. Ciência no feitiço: técnica vocal e "o formante do ator". Sala Preta - Revista da PPG em Artes Cênicas - ECA - USP, vol. 7, n. 7, 2007. Disponível em: <http:// www.revistas.usp.br/salapreta/issue/view/4699/showToc>. Acesso em: 30 set. 2013.

McMILLAN, D.; FESENFELD, M. Beckett in the Theatre. London: John Calder/New York: Riverrun Press, 1988.

RYNGAERT, J. Ler o Teatro Contemporâneo. São Paulo: Martins Fontes, 1998.

SANTOS, T. A. O. A coisa e o olho: uma abordagem da direção de atores no teatro de Samuel Beckett. São Paulo: 2013. Dissertação (Mestrado), Instituto de Artes, Universidade Estadual Paulista.

THOMAS, G. "Molloy traz estilo deliberadamente ingênuo de Beckett". Folha de S. Paulo. São Paulo, 26 de março 1988. Seção: Livros, Primeira leitura.

Recebido em 10/05/2014 Aprovado em 27/06/2014 